\title{
Prognostic value of ECG findings for total, cardiovascular disease, and coronary heart disease death in men and women
}

\author{
D De Bacquer, G De Backer, M Kornitzer, H Blackburn
}

\begin{abstract}
Objective-To study abnormalities in the resting ECG as independent predictors for all cause, cardiovascular disease (CVD), and coronary heart disease (CHD) mortality in a population based random sample of men and women, and to explore whether their prognostic value is different between sexes.

Design and subjects-An age and sex stratified random sample was selected from the total Belgian population aged 25 to 74 years. Baseline data were gathered and resting ECGs were classified according to Minnesota code criteria. The sample was then followed for at least $\mathbf{1 0}$ years with respect to cause specific death. Results are based on observations from 5208 men and 4746 women free from prevalent CHD at the start of the follow up period.
\end{abstract}

Results-Although the prevalence of major abnormalities in general was comparable between sexes, women had more ischaemic findings, ST segment changes, and abnormal $T$ waves on their baseline ECG, while men showed more arrhythmias, bundle branch blocks, and left ventricular hypertrophy. Fitting the multiplicative effect on subsequent mortality between all ECG classifications under study and sex indicated that the prognostic value of ECG changes was equal in women and men. Independently of other risk factors and other major ECG changes, almost all ECG classifications were significantly related to all cause, CVD, and CHD mortality. The most predictive ECG findings for CVD death were ST segment depression (risk ratio (RR) 4.71), major ECG findings (RR 3.26), left ventricular hypertrophy (RR 2.79), bundle branch blocks (RR 2.58), $T$ wave flattening (RR 2.47), ischaemic ECG findings (RR 2.35), and arrhythmias (RR 2.15). The prognostic value of major ECG findings for CVD and CHD death was more powerful than well established cardiovascular risk factors.

Conclusions-Abnormalities in the baseline ECG are strongly associated with subsequent all cause, CVD, and CHD mortality. Their predictive value was similar for men and women.

(Heart 1998;80:570-577)

Keywords: ECG; mortality; Minnesota code; risk factors
As part of the standard routine examination procedure in cardiac medicine, the resting ECG has proved its value as a diagnostic tool for detecting heart disease. Apart from their use in the clinical context, ECGs from apparently healthy subjects have been used to study the prevalence, correlates, and the predictive value of asymptomatic heart diseases in the general population. ${ }^{1}$ Since the introduction of the Minnesota codes ${ }^{2}$ several epidemiological studies ${ }^{3-24}$ have concentrated on the association between initial ECG abnormalities and subsequent fatal and non-fatal cardiovascular disease (CVD) in a standardised way. However, most of these studies were based on population samples of men; only a few reports were dealing with the prognostic role of ECGs in women.

This study investigates the independent prognostic value of initial ECG changes for mortality from all causes, CVD, and coronary heart disease (CHD) in a random sample of men and women free from symptomatic CHD at baseline, focusing in particular on possible differences between the sexes.

\section{Methodology}

STUDY POPULATION

The results are based on observations made in men and women who took part in the Belgian inter-university research on nutrition and health (BIRNH) study. This study, in which baseline measurements were made in the years 1981 to 1984 , focuses on the distribution of cardiovascular risk factors and nutritional habits in Belgium and their relation to total and cause specific mortality. The detailed methodology and results have been published. ${ }^{25}{ }^{26} \mathrm{An}$ age and sex stratified population sample of subjects 25 to 74 years old was selected at random from 42 of the 43 Belgian geographic districts. To achieve a sufficient sample size under circumstances in which little pressure was put on invited eligible subjects, a sample of more than 30000 persons was selected. The participation rate was $36.5 \%$, resulting in 11302 subjects taking part in the study (5949 men and 5353 women). A $10 \%$ random sample of the non-participants was selected and invited to answer a number of questions related to smoking and nutritional habits, which revealed that no differences existed between participants and non-participants with respect to lifestyle. ${ }^{26}$ It was not feasible, however, to compare participants and non-participants with regard to their ECG patterns.

In the initial database there were 11048 subjects with complete baseline ECG data. 
Data used in the present analysis are from 5208 men and 4746 women who were free from prevalent CHD at baseline, defined as being free from angina pectoris or a positive history of acute myocardial infarction according to the Rose questionnaire, ${ }^{27}$ and having no $\mathrm{Q}$ wave evidence of an old myocardial infarction on their resting ECG at baseline $(\mathrm{Q}$ and $\mathrm{QS}$ patterns, Minnesota coding criteria $\mathrm{I}_{1,2}$ ).

The study design and methodology was approved by the ethics committees of the University of Gent and the Free University of Brussels.

FOLLOW UP

The global sample was followed for at least 10 years for cause specific mortality, the follow up being complete in $99 \%$ of the participants. Vital status was checked through local community registers and causes of death were ascertained from the family doctor and/or the doctor who completed the death certificate. Where appropriate, more information on the exact cause of death was collected from hospital or medical records. According to the ninth revision of the International Classification of Diseases $(\mathrm{ICD})^{28}$ we considered as cause of death from CVD all codes ranging from 390 to 459. Cases of CHD mortality were defined as those with ICD codes 410 to 414 . After 10 years 559 men and 224 women had died; 166 men and 73 women were classified as CVD deaths, and 95 men and 36 women died from CHD.

RESTING ECG

Using a three channel Hewlett-Packard device type 1516B, a 12 lead ECG lasting an average of 16 seconds was taken in supine position in accordance with classic recommendations. All tracings were coded by a trained physician on the basis of Minnesota criteria. ${ }^{2}$ In order to obtain groups sufficiently large to allow for reliable conclusions, ECG findings were further pooled using several classifications. According to the criteria of the pooling project ${ }^{29}$ major ECG abnormalities consist of ST segment depression (Minnesota codes $\mathrm{IV}_{1-2}$ ), $\mathrm{T}$ wave inversion (codes $\mathrm{V}_{1-2}$ ), complete or second degree atrioventricular (AV) block (codes $\mathrm{VI}_{1-2}$ ), complete left or right bundle branch block (codes VII $_{1-2}$ ), frequent premature beats (code VIII $)$, and atrial fibrillation or flutter (code $\mathrm{VIII}_{3}$ ). Minor ECG abnormalities include borderline $\mathrm{Q}$ wave (code $\mathrm{I}_{3}$ ), left or right axis deviation (codes $\mathrm{II}_{1-2}$ ), QRS high voltage (codes III $_{1-2}$ ), borderline ST segment depression (code $\mathrm{IV}_{3}$ ), $\mathrm{T}$ wave flattening (code $\mathrm{V}_{3}$ ), and QRS low voltage (code IX $\mathrm{X}_{1}$ ). Since a relatively high proportion of the subjects with minor abnormalities also showed signs of major ECG changes $(9 \%$ in men, $8 \%$ in women), the influence of the presence of isolated minor abnormalities on mortality was also studied. Signs of an ischaemic ECG were defined as the presence of either a borderline $\mathrm{Q}$ wave (code $\mathrm{I}_{3}$ ), significant or borderline ST segment depression (codes $\mathrm{IV}_{1-3}$ ), deep or moderate $\mathrm{T}$ wave inversion (codes $\mathrm{V}_{1-3}$ ), or evidence of complete left bundle branch block
Table 1 Definition and classification of ECG findings: the BIRNH study

\begin{tabular}{ll}
\hline & Minnesota codes \\
\hline Major ECG findings & $\mathrm{IV}_{1-2}$ or $\mathrm{V}_{1-2}$ or $\mathrm{VI}_{1-2}$ or $\mathrm{VII}_{1-2}$ or $\mathrm{VIII}_{1-3}$ \\
Minor ECG findings & $\mathrm{I}_{3}$ or $\mathrm{II}_{1-2}$ or $\mathrm{II}_{1-2}$ or $\mathrm{IV}_{3}$ or $\mathrm{V}_{3}$ or II \\
Only minor ECG & Minor ECG changes but no major \\
$\quad$ findings & ECG changes \\
Ischaemic ECG & \\
findings & $\mathrm{I}_{3}$ or $\mathrm{IV}_{1-3}$ or $\mathrm{V}_{1-3}$ or $\mathrm{VII}_{1}$ \\
ST depression & $\mathrm{IV}_{1-3}$ \\
Abnormal T wave & $\mathrm{V}_{1-3}$ \\
$\begin{array}{l}\text { Arrhythmias } \\
\text { Bundle branch blocks }\end{array}$ & $\mathrm{VIII}_{1-6}$ or $\mathrm{VI}_{1-2,4}$ \\
Left ventricular & $\mathrm{VII}_{1-2,4}$ \\
hypertrophy & $\mathrm{III}_{1}$ and $\left(\mathrm{IV}_{1-3}\right.$ or $\left.\mathrm{V}_{1-3}\right)$ \\
Left axis deviation & $\mathrm{II}_{1}$ \\
\hline
\end{tabular}

(code $\mathrm{VII}_{1}$ ). Finally, separate analyses were performed for ST depression (codes $\mathrm{IV}_{1-3}$ ), abnormal $\mathrm{T}$ wave (codes $\mathrm{V}_{1-3}$ ), arrhythmias or AV blocks (codes VIII VI-6 $_{\text {or codes }} \mathrm{VI}_{1-2,4}$ ), bundle branch blocks (codes $\mathrm{VII}_{1-2,4}$ ), and left axis deviation (code $\mathrm{II}_{1}$ ). Left ventricular hypertrophy (LVH) was defined as the joint occurrence of an isolated hypertrophy (code III $_{1}$ ) in combination with either an ST depression (codes $\mathrm{IV}_{1-3}$ ) or a $\mathrm{T}$ wave change (codes $\mathrm{V}_{1-3}$ ). A comprehensive overview of the above definitions is given in table 1 .

\section{COVARIATES}

Clinical and biochemical measurements were made on all participating subjects using standardised and validated methods. Blood pressure was determined using a random sphygmomanometer, and a non-fasting blood sample was taken from an antecubital vein in supine position and analysed for serum total and high density lipoprotein (HDL) cholesterol. Information on smoking behaviour, history of diabetes mellitus, and current antihypertensive drug treatment was obtained by questionnaire. The body mass index (BMI) was calculated as weight ( $\mathrm{kg})$ divided by height squared $\left(\mathrm{m}^{2}\right)$. Hypertension in an individual was defined according to World Health Organisation criteria as systolic blood pressure $\geqslant 160 \mathrm{~mm} \mathrm{Hg}$, diastolic blood pressure $\geqslant 95 \mathrm{~mm} \mathrm{Hg}$, and/or receiving antihypertensive drug treatment.

STATISTICAL METHODS

All prevalence rates of ECG findings and mortality rates were adjusted for age using the direct standardisation method with the age structure of the total Belgian male and female population of 1982 as reference. Statistical analysis of the association between initial ECG findings and subsequent mortality was performed by fitting Cox proportional hazard

Table 2 Characteristics of the study sample: the BIRNH study

\begin{tabular}{lll}
\hline & $\begin{array}{l}\text { Men } \\
(n=5208)\end{array}$ & $\begin{array}{l}\text { Women } \\
(n=4746)\end{array}$ \\
\hline Age (years) & $48.7(13.3)$ & $48.1(12.9)$ \\
BMI (kg/m $\left.{ }^{2}\right)$ & $25.9(3.5)$ & $25.9(4.5)$ \\
Systolic blood pressure (mm Hg) & $135.9(17.7)$ & $131.2(20.6)$ \\
Total cholesterol (mg/dl) & $233.1(43.5)$ & $234.9(47.6)$ \\
HDL cholesterol (mg/dl) & $49.0(12.3)$ & $59.8(13.8)$ \\
Current smoking & $50.3 \%$ & $16.7 \%$ \\
Diabetic & $1.8 \%$ & $2.0 \%$ \\
Antihypertensive drug use & $7.0 \%$ & $13.1 \%$ \\
\hline
\end{tabular}

Values are mean (SD) unless otherwise stated. 
Table 3 Age standardised* prevalences of initial ECG findings: the BIRNH study

\begin{tabular}{lll}
\hline & Men $(n=5208)$ & Women $(n=4746)$ \\
\hline Any coded ECG finding & $31.9 \%(1687)$ & $26.3 \%(1230)$ \\
Major ECG findings & $3.7 \%(217)$ & $3.1 \%(138)$ \\
Minor ECG findings & $15.2 \%(830)$ & $13.2 \%(615)$ \\
Only minor ECG findings & $14.1 \%(763)$ & $12.1 \%(565)$ \\
Ischaemic ECG findings & $7.8 \%(445)$ & $11.1 \%(516)$ \\
ST depression & $1.6 \%(97)$ & $2.7 \%(124)$ \\
Abnormal T wave & $6.1 \%(345)$ & $9.6 \%(449)$ \\
Arrhythmias & $6.2 \%(326)$ & $4.7 \%(222)$ \\
Bundle branch blocks & $1.4 \%(79)$ & $0.8 \%(33)$ \\
Left ventricular hypertrophy & $0.8 \%(42)$ & $0.5 \%(21)$ \\
Left axis deviation & $5.0 \%(282)$ & $2.9 \%(132)$ \\
\hline
\end{tabular}

*Using the total Belgian population from 1982 as reference.

Table 4 Age standardised ${ }^{\star}$ ratest of all cause, CVD, and CHD mortality according to initial ECG findings: the BIRNH study

\begin{tabular}{|c|c|c|}
\hline & Men & Women \\
\hline $\begin{array}{l}\text { All cause mortality } \\
\text { Total sample } \\
\text { Any coded ECG finding } \\
\text { Major ECG findings } \\
\text { Minor ECG findings } \\
\text { Only minor ECG findings } \\
\text { Ischaemic ECG findings } \\
\text { ST depression } \\
\text { Abnormal T wave } \\
\text { Arrhythmias } \\
\text { Bundle branch block } \\
\text { Left ventricular hypertrophy } \\
\text { Left axis deviation }\end{array}$ & $\begin{array}{l}10.4(559 / 5208) \ddagger \\
11.7(246 / 1687) \\
20.6(71 / 217) \\
11.6(137 / 830) \\
11.2(118 / 763) \\
17.2(115 / 445) \\
28.8(42 / 97) \\
16.4(86 / 345) \\
13.6(55 / 326) \\
23.4(27 / 79) \\
13.2(11 / 42) \\
9.2(45 / 282)\end{array}$ & $\begin{array}{l}5.3(224 / 4746) \\
5.8(89 / 1230) \\
9.1(25 / 138) \\
6.2(57 / 615) \\
5.9(48 / 565) \\
6.3(52 / 516) \\
9.4(21 / 124) \\
6.3(44 / 449) \\
6.0(16 / 222) \\
12.7(8 / 33) \\
6.2(3 / 21) \\
6.1(13 / 132)\end{array}$ \\
\hline $\begin{array}{l}\text { CVD mortality } \\
\text { Total sample } \\
\text { Any coded ECG finding } \\
\text { Major ECG findings } \\
\text { Minor ECG findings } \\
\text { Only minor ECG findings } \\
\text { Ischaemic ECG findings } \\
\text { ST depression } \\
\text { Abnormal T wave } \\
\text { Arrhythmias } \\
\text { Bundle branch block } \\
\text { Left ventricular hypertrophy } \\
\text { Left axis deviation }\end{array}$ & $\begin{array}{l}3.1(166 / 5208) \\
4.2(90 / 1687) \\
10.1(36 / 217) \\
4.1(48 / 830) \\
3.8(39 / 763) \\
7.8(51 / 445) \\
15.7(22 / 97) \\
7.6(39 / 345) \\
5.9(24 / 326) \\
11.1(12 / 79) \\
7.6(6 / 42) \\
2.8(14 / 282)\end{array}$ & $\begin{array}{l}1.8(73 / 4746) \\
2.5(40 / 1230) \\
6.7(19 / 138) \\
2.6(27 / 615) \\
2.0(18 / 565) \\
3.5(32 / 516) \\
8.2(19 / 124) \\
3.8(29 / 449) \\
2.7(7 / 222) \\
4.0(4 / 33) \\
4.1(2 / 21) \\
1.9(5 / 132)\end{array}$ \\
\hline $\begin{array}{l}\text { CHD mortality } \\
\text { Total sample } \\
\text { Any coded ECG finding } \\
\text { Major ECG findings } \\
\text { Minor ECG findings } \\
\text { Only minor ECG findings } \\
\text { Ischaemic ECG findings } \\
\text { ST depression } \\
\text { Abnormal T wave } \\
\text { Arrhythmias } \\
\text { Bundle branch block } \\
\text { Left ventricular hypertrophy } \\
\text { Left axis deviation }\end{array}$ & $\begin{array}{l}1.8(95 / 5208) \\
2.3(49 / 1687) \\
4.6(15 / 217) \\
1.9(25 / 830) \\
2.1(24 / 763) \\
3.1(23 / 445) \\
7.9(11 / 97) \\
3.6(20 / 345) \\
3.0(12 / 326) \\
4.3(5 / 79) \\
2.8(2 / 42) \\
2.3(12 / 282)\end{array}$ & $\begin{array}{l}0.9(36 / 4746) \\
1.3(20 / 1230) \\
2.4(8 / 138) \\
1.5(14 / 615) \\
1.2(10 / 565) \\
1.4(13 / 516) \\
2.0(5 / 124) \\
1.6(12 / 449) \\
1.4(4 / 222) \\
2.0(2 / 33) \\
2.1(1 / 21) \\
1.2(3 / 132)\end{array}$ \\
\hline
\end{tabular}

${ }^{\star}$ Using the total Belgian population from 1982 as reference.

†Per 1000 person-years.

$\ddagger$ Between parentheses: number of deaths/size of subgroup.

models $^{31}$ with additional covariates of age (years), BMI $\left(\mathrm{kg} / \mathrm{m}^{2}\right)$, current smoking (yes/ no), systolic blood pressure $(\mathrm{mm} \mathrm{Hg})$, total and HDL cholesterol (mg/dl), diabetic status (yes/no), and antihypertensive drug use (yes/ no). Regarding the possible multiplicity of ECG findings, the effect of each ECG classification on mortality was further adjusted for the presence of additional major abnormalities other than the one under study. The statistical significance of a variable in the model was determined according to the Wald $\chi^{2}$ statistic and the strength of the association is given by the adjusted hazard ratios (risk ratios (RRs)), which are given with $95 \%$ confidence intervals (CIs). In order to test whether the prognostic value of a certain ECG change was similar for men and women, a formal interaction test was performed between ECG findings and sex. The significance of the interaction was evaluated by comparing the log likelihood functions of the fitted models with and without the multiplicative effect. Under the null hypothesis of no interaction, minus double this difference follows a $\chi^{2}$ distribution with 1 degree of freedom. All models were checked on the assumption of proportionality of hazards. The global level for significance was taken as $\alpha=0.05$ and all analyses were performed using SAS software. ${ }^{32}$

\section{Results}

Some characteristics of the sample at the start of the follow up period are given in table 2. The cardiovascular profile is rather typical for Belgian men and women at the beginning of the 1980 s, in particular the high prevalence of cigarette smoking.

Table 3 displays the age standardised prevalences of the ECG findings under study. In both men and women, one in four subjects had at least one change in their baseline ECG. The prevalence of major as well as minor abnormalities was very similar in both sexes while ST segment changes, abnormal $\mathrm{T}$ waves, and in general ischaemia-like ECG changes, were more prevalent in women. This sex difference was largely caused by differences in the occurrence of Minnesota codes $\mathrm{IV}_{3}$ and $V_{3}$, both known to be more prevalent in women. The higher prevalence of these abnormalities in women was consistently observed in all age groups. In contrast, arrhythmias, bundle branch blocks, left axis deviations, and LVH were about twice as frequent in men as in women.

The age standardised all cause mortality rates over the whole follow up period were 10.4 and 5.3 per 1000 person-years in men and women (table 4). For CVD and CHD mortality these rates were 3.1 and 1.8 for men, and 1.8 and 0.9 for women, respectively. In both sexes, the highest rates for all cause, CVD, and CHD mortality were found in the groups with an ST depression, bundle branch blocks, or major ECG changes in general.

The age adjusted ratios of these mortality rates, comparing each group of subjects characterised by a certain baseline ECG finding with the group of individuals not showing that specific ECG change on their initial ECG, are shown in table 5. The mortality RRs after multivariate adjustment for age, BMI, systolic blood pressure, total and HDL cholesterol, smoking, diabetic status, use of antihypertensive drugs, and other major ECG findings are shown in table 6 . Although not always significant for women because of lack of power, in most cases the magnitude of the adjusted RRs are quite comparable between men and women. More formally, as can be judged from the several $\chi^{2}$ statistics for evaluating the difference of RR between both sexes, none of the multiplicative effects turned out to be significant at the $10 \%$ level. Hence, it can be concluded from our data that the predictive value of all ECG findings under study for all cause, CVD, and CHD mortality is very similar for men and women. As a result, data from both sexes can be 
Table 5 Age adjusted relative risks for all cause, CVD, and CHD mortality related to initial ECG findings: the BIRNH study

\begin{tabular}{|c|c|c|}
\hline & Men RR $(95 \% C I)$ & Women RR $(95 \%$ CI) \\
\hline \multicolumn{3}{|l|}{ All cause mortality } \\
\hline Any coded ECG finding & $1.18(0.99$ to 1.40$)$ & $1.14(0.87$ to 1.50$)$ \\
\hline Major ECG findings & $1.71(1.32 \text { to } 2.20)^{\star \star \star \star}$ & $1.87(1.22 \text { to } 2.85)^{\star \star}$ \\
\hline Minor ECG findings & $1.06(0.87$ to 1.29$)$ & $1.14(0.84$ to 1.54$)$ \\
\hline Only minor ECG findings & $1.02(0.83$ to 1.25$)$ & $1.04(0.75$ to 1.44$)$ \\
\hline Ischaemic ECG findings & $1.59(1.29 \text { to } 1.96)^{\star \star \star}$ & $1.18(0.86$ to 1.62$)$ \\
\hline ST depression & $2.61(1.90 \text { to } 3.59)^{\star \star \star \star}$ & $2.01(1.28 \text { to } 3.16)^{\star \star}$ \\
\hline Abnormal $\mathrm{T}$ wave & $1.55(1.23 \text { to } 1.96)^{\star \star \star}$ & $1.15(0.82$ to 1.61$)$ \\
\hline Arrhythmias & $1.32(0.99$ to 1.74$)$ & $1.12(0.67$ to 1.86$)$ \\
\hline Bundle branch block & $1.60(1.08 \text { to } 2.36)^{\star}$ & $2.06(1.01 \text { to } 4.20)^{\star}$ \\
\hline Left ventricular hypertrophy & $1.50(0.82$ to 2.72$)$ & $1.22(0.39$ to 3.81$)$ \\
\hline Left axis deviation & $0.88(0.64$ to 1.19$)$ & $1.12(0.64$ to 1.97$)$ \\
\hline \multicolumn{3}{|l|}{ CVD mortality } \\
\hline Any coded ECG finding & $1.70(1.25 \text { to } 2.32)^{\star \star \star}$ & $1.82(1.14 \text { to } 2.90)^{\star}$ \\
\hline Major ECG findings & $3.04(2.08 \text { to } 4.43)^{\star \star \star}$ & $4.32(2.53 \text { to } 7.38)^{\star \star \star}$ \\
\hline Minor ECG findings & $1.25(0.89$ to 1.76$)$ & $1.67(1.03 \text { to } 2.70)^{\star}$ \\
\hline Only minor ECG findings & $1.10(0.77$ to 1.58$)$ & $1.08(0.63$ to 1.84$)$ \\
\hline Ischaemic ECG findings & $2.58(1.84 \text { to } 3.61)^{\star \star \star \star}$ & $2.59(1.62 \text { to } 4.15)^{\star \star \star}$ \\
\hline ST depression & $4.58(2.90 \text { to } 7.21)^{\star \star \star \star}$ & $6.04(3.57 \text { to } 10.23)^{\star \star \star}$ \\
\hline Abnormal $\mathrm{T}$ wave & $2.48(1.73 \text { to } 3.57)^{\star \star \star}$ & $2.68(1.67 \text { to } 4.32)^{\star \star \star}$ \\
\hline Arrhythmias & $1.96(1.27 \text { to } 3.03)^{\star \star}$ & $1.32(0.60$ to 2.90$)$ \\
\hline Bundle branch block & $2.26(1.25 \text { to } 4.09)^{\star \star}$ & $2.45(0.89$ to 6.77$)$ \\
\hline Left ventricular hypertrophy & $2.61(1.15 \text { to } 5.90)^{\star}$ & $2.04(0.50$ to 8.34$)$ \\
\hline Left axis deviation & $0.87(0.50$ to 1.51$)$ & $1.16(0.47$ to 2.88$)$ \\
\hline \multicolumn{3}{|l|}{ CHD mortality } \\
\hline Any coded ECG finding & $1.56(1.04 \text { to } 2.35)^{\star}$ & $1.95(0.99$ to 3.80$)$ \\
\hline Major ECG findings & $2.09(1.19 \text { to } 3.67)^{\star}$ & $3.64(1.63 \text { to } 8.13)^{\star \star}$ \\
\hline Minor ECG findings & $1.12(0.71$ to 1.79$)$ & $1.89(0.96$ to 3.73$)$ \\
\hline Only minor ECG findings & $1.24(0.78$ to 1.99$)$ & $1.32(0.63$ to 2.75$)$ \\
\hline Ischaemic ECG findings & $1.88(1.17 \text { to } 3.04)^{\star \star}$ & $1.94(0.97$ to 3.88$)$ \\
\hline ST depression & $3.99(2.11 \text { to } 7.54)^{\star \star \star}$ & $2.78(1.08 \text { to } 7.19)^{\star}$ \\
\hline Abnormal $\mathrm{T}$ wave & $2.20(1.34 \text { to } 3.63)^{\star \star}$ & $2.10(1.04 \text { to } 4.24)^{\star}$ \\
\hline Arrhythmias & $1.70(0.93$ to 3.12$)$ & $1.63(0.57$ to 4.64$)$ \\
\hline Bundle branch block & $1.65(0.67$ to 4.10$)$ & $2.65(0.63$ to 11.19$)$ \\
\hline Left ventricular hypertrophy & $1.53(0.38$ to 6.22$)$ & $2.16(0.30$ to 15.89$)$ \\
\hline Left axis deviation & $1.40(0.76$ to 2.58$)$ & $1.47(0.45$ to 4.82$)$ \\
\hline
\end{tabular}

${ }^{\star} \mathrm{p}<0.05 ;{ }^{\star \star} \mathrm{p}<0.01 ;{ }^{\star \star \star} \mathrm{p}<0.001$ pooled in order to estimate the impact of initial ECG changes on subsequent mortality with more precision (table 6).

For all cause mortality, significant associations were found for ST segment depression (RR 2.26), major ECG changes and bundle branch blocks (both RR 1.76), ischaemic ECG changes and negative $T$ waves (both RR 1.37), and arrhythmias (RR 1.35). Almost all ECG classifications were independently associated with CVD mortality with most RRs exceeding the value of 2. An ST depression on the baseline ECG and major ECG changes in general showed the strongest predictive power for CVD mortality (RR 4.71 and 3.26, respectively) as well as for CHD mortality (RR 2.97 and 2.33, respectively). In our study, only minor ECG abnormalities and left axis deviations were not significantly associated with all cause mortality, or with CVD or CHD mortality. A graphical overview of the associations between baseline ECG findings and CVD and CHD mortality, as observed in our study, is given in fig 1 .

In order to estimate quantitatively the relative impact of ECG findings on mortality compared to other classic risk factors, a Cox proportional hazards model was fitted estimating the independent effect of several known cardiovascular risk factors on CVD and CHD mortality rates (table 7 ). Clearly, in our sample major ECG changes were stronger independent predictors for CVD and CHD mortality than hypertension, hyperlipidaemia, male sex, smoking, diabetes, or obesity. Only the effect of

Table 6 Multivariately adjusted risk ratios for all cause, CVD, and CHD mortality related to initial ECG findings: the BIRNH study

\begin{tabular}{|c|c|c|c|c|}
\hline & Men RR $(95 \% C I)$ & Women RR $(95 \%$ CI) & $\chi^{2}$ interaction & All subjects RR (95\% CI) \\
\hline \multicolumn{5}{|l|}{ All cause mortality } \\
\hline Any coded ECG finding & $1.14(0.96$ to 1.35$)$ & $1.06(0.80$ to 1.39$)$ & 0.04 & $1.11(0.96$ to 1.28$)$ \\
\hline Major ECG findings & $1.78(1.38 \text { to } 2.30)^{\star \star \star}$ & $1.69(1.11 \text { to } 2.51)^{\star}$ & 0.01 & $1.76(1.42 \text { to } 2.19)^{\star \star \star}$ \\
\hline Minor ECG findings & $0.99(0.81$ to 1.20$)$ & $1.06(0.78$ to 1.44$)$ & 0.40 & $0.98(0.83$ to 1.16$)$ \\
\hline Ischaemic ECG findings & $1.53(1.23 \text { to } 1.89)^{\star \star \star}$ & $1.11(0.81$ to 1.54$)$ & 1.81 & $1.37(1.14 \text { to } 1.63)^{\star \star \star \star}$ \\
\hline ST depression & $2.52(1.82 \text { to } 3.49)^{\star \star \star}$ & $1.89(2.66 \text { to } 6.88)^{\star \star}$ & 0.73 & $2.26(1.73 \text { to } 2.95)^{\star \star \star}$ \\
\hline Abnormal $\mathrm{T}$ wave & $1.56(1.23 \text { to } 1.98)^{\star \star \star}$ & $1.10(0.78$ to 1.55$)$ & 1.92 & $1.37(1.13 \text { to } 1.66)^{\star \star}$ \\
\hline Arrhythmias & $1.36(1.03 \text { to } 1.80)^{\star}$ & $1.03(0.61$ to 1.72$)$ & 0.75 & $1.35(1.06 \text { to } 1.73)^{\star}$ \\
\hline Bundle branch block & $1.64(1.11 \text { to } 2.43)^{\star}$ & $1.76(0.86$ to 3.63$)$ & 0.08 & $1.76(1.25 \text { to } 2.49)^{\star \star}$ \\
\hline Left ventricular hypertrophy & $1.53(0.84$ to 2.80$)$ & $1.10(0.35$ to 3.45$)$ & 0.19 & $1.52(0.89$ to 2.59$)$ \\
\hline Left axis deviation & $0.86(0.63$ to 1.17$)$ & $1.11(0.63$ to 1.96$)$ & 0.86 & $0.96(0.73$ to 1.26$)$ \\
\hline \multicolumn{5}{|l|}{ CVD mortality } \\
\hline Any coded ECG finding & $1.54(1.13 \text { to } 2.11)^{\star \star}$ & $1.60(0.99$ to 2.56$)$ & 0.16 & $1.57(1.21 \text { to } 2.03)^{\star \star \star}$ \\
\hline Major ECG findings & $3.07(2.09 \text { to } 4.50)^{\star \star \star}$ & $3.87(2.26 \text { to } 6.65)^{\star \star \star \star}$ & 0.90 & $3.26(2.39 \text { to } 4.44)^{\star \star \star \star}$ \\
\hline Minor ECG findings & $1.10(0.78$ to 1.55$)$ & $1.45(0.89$ to 2.36$)$ & 1.65 & $1.17(0.88$ to 1.55$)$ \\
\hline Ischaemic ECG findings & $2.36(1.66 \text { to } 3.35)^{\star \star \star \star}$ & $2.35(1.44 \text { to } 3.85)^{\star \star \star}$ & 0.16 & 2.35 (1.77 to 3.12$)^{\star \star \star}$ \\
\hline ST depression & $4.28(2.66 \text { to } 6.88)^{\star \star \star}$ & $6.00(3.45 \text { to } 10.41)^{\star \star \star}$ & 1.13 & 4.71 (3.30 to 6.72$)^{\star \star \star}$ \\
\hline Abnormal $\mathrm{T}$ wave & $2.40(1.65 \text { to } 3.50)^{\star \star \star}$ & $2.55(1.55 \text { to } 4.21)^{\star \star \star}$ & 0.27 & $2.47(1.83 \text { to } 3.32)^{\star \star \star}$ \\
\hline Arrhythmias & $2.44(1.57 \text { to } 3.80)^{\star \star \star}$ & $1.52(0.68$ to 3.41$)$ & 1.20 & $2.15(1.46 \text { to } 3.17)^{\star \star \star \star}$ \\
\hline Bundle branch block & $2.63(1.44 \text { to } 4.79)^{\star \star}$ & $2.56(0.89$ to 7.39$)$ & 0.02 & $2.58(1.53 \text { to } 4.33)^{\star \star \star}$ \\
\hline Left ventricular hypertrophy & $3.14(1.36 \text { to } 7.26)^{\star \star}$ & $2.20(0.53$ to 9.16$)$ & 0.21 & $2.79(1.36 \text { to } 5.71)^{\star \star}$ \\
\hline Left axis deviation & $1.00(0.57$ to 1.75$)$ & $1.45(0.58$ to 3.66$)$ & 0.58 & $1.10(0.68$ to 1.77$)$ \\
\hline \multicolumn{5}{|l|}{ CHD mortality } \\
\hline Any coded ECG finding & $1.43(0.95$ to 2.16$)$ & $1.59(0.81$ to 3.14$)$ & 0.23 & $1.48(1.04 \text { to } 2.11)^{\star}$ \\
\hline Major ECG findings & $2.11(1.19 \text { to } 3.72)^{\star \star}$ & $3.07(1.36 \text { to } 6.94)^{\star \star}$ & 0.84 & $2.33(1.47 \text { to } 3.70)^{\star \star \star \star}$ \\
\hline Minor ECG findings & $0.99(0.62$ to 1.59$)$ & $1.55(0.78$ to 3.09$)$ & 1.63 & $1.13(0.77$ to 1.67$)$ \\
\hline Ischaemic ECG findings & $1.68(1.03 \text { to } 2.75)^{\star}$ & $1.68(0.81$ to 3.49$)$ & 0.01 & $1.66(1.11 \text { to } 2.50)^{\star}$ \\
\hline ST depression & $3.49(1.79 \text { to } 6.79)^{\star \star \star}$ & $2.61(0.99$ to 6.92$)$ & 0.23 & $2.97(1.72 \text { to } 5.15)^{\star \star \star}$ \\
\hline Abnormal $\mathrm{T}$ wave & $2.05(1.23 \text { to } 3.43)^{\star \star}$ & $1.86(0.89$ to 3.90$)$ & 0.02 & $1.97(1.30 \text { to } 3.00)^{\star \star}$ \\
\hline Arrhythmias & $2.01(1.09 \text { to } 3.73)^{\star}$ & $1.66(0.56$ to 4.94$)$ & 0.14 & $1.94(1.14 \text { to } 3.30)^{\star}$ \\
\hline Bundle branch block & $1.83(0.74$ to 4.55$)$ & $2.25(0.50$ to 10.15$)$ & 0.05 & $1.91(0.88$ to 4.14$)$ \\
\hline Left ventricular hypertrophy & $1.84(0.44$ to 7.64$)$ & $1.89(0.25$ to 14.13$)$ & 0.01 & $1.86(0.58$ to 5.93$)$ \\
\hline Left axis deviation & $1.46(0.79$ to 2.72$)$ & $1.63(0.48$ to 5.52$)$ & 0.09 & $1.52(0.87$ to 2.63$)$ \\
\hline
\end{tabular}

${ }^{\star} \mathrm{p}<0.05 ;{ }^{\star \star} \mathrm{p}<0.01 ;{ }^{\star \star \star} \mathrm{p}<0.001$

RRs adjusted for age, BMI, systolic blood pressure, total and HDL cholesterol, smoking, diabetic status, intake of antihypertensive drugs, and other major ECG changes (and sex in the analysis of both sexes combined). 

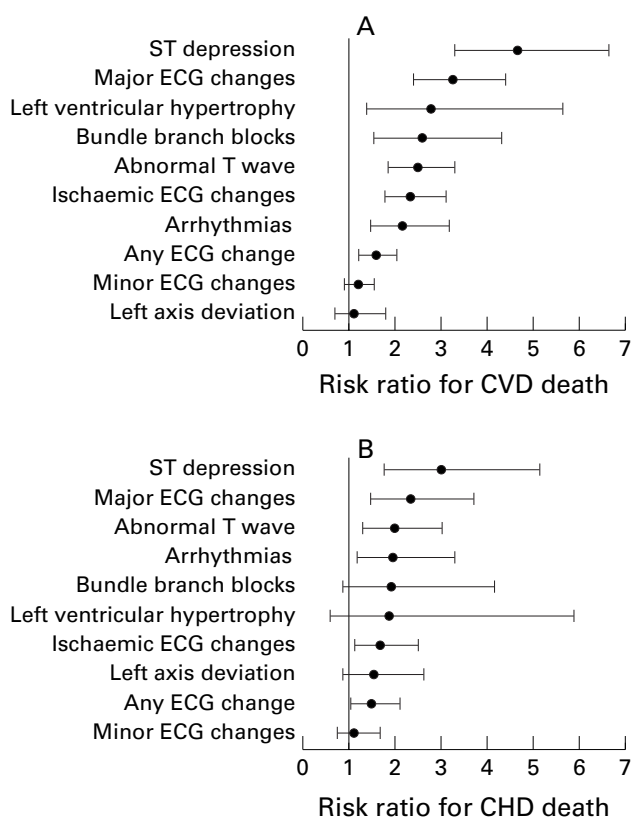

Figure 1 Multivariately adjusted risk ratios for (A) cardiovascular disease (CVD) and (B) coronary heart disease $(C H D)$ mortality after 10 years in relation to different classifications of ECG findings - the BIRNH study.

Table 7 Multivariately adjusted relative risks for CVD and CHD mortality related to major and minor ECG findings and to other cardiovascular risk factors: the BIRNH study

\begin{tabular}{ll}
\hline & $R R(95 \%$ CI $)$ \\
\hline CVD mortality & \\
Age $\geqslant 60$ years & $7.61(5.59 \text { to } 10.36)^{\star \star \star}$ \\
Major ECG findings & $3.88(2.84 \text { to } 5.31)^{\star \star \star}$ \\
Hypertension & $2.18(1.66 \text { to } 2.86)^{\star \star \star}$ \\
Male sex & $1.87(1.37 \text { to } 2.55)^{\star \star \star}$ \\
Diabetes & $1.64(0.95 \text { to } 2.84)^{\star}$ \\
Smoking & $1.45(1.09 \text { to } 1.94)^{\star}$ \\
Total/HDL cholesterol $\geqslant 5$ & $1.26(0.97$ to 1.64$)$ \\
Minor ECG findings & $1.26(0.95$ to 1.68$)$ \\
Obesity & $1.13(0.83$ to 1.54$)$ \\
& \\
CHD mortality & \\
Age $\geqslant 60$ years & $6.11(4.11 \text { to } 9.07)^{\star \star \star \star}$ \\
Major ECG findings & $2.89(1.82 \text { to } 4.59)^{\star \star \star}$ \\
Hypertension & $2.52(1.75 \text { to } 3.62)^{\star \star \star}$ \\
Total/HDL cholesterol $\geqslant 5$ & $2.28(1.57 \text { to } 3.29)^{\star \star \star \star}$ \\
Smoking & $1.76(1.20 \text { to } 2.60)^{\star \star}$ \\
Male sex & $1.73(1.12 \text { to } 2.67)^{\star}$ \\
Minor ECG findings & $1.27(0.86$ to 1.87$)$ \\
Diabetes & $0.87(0.32$ to 2.38$)$ \\
Obesity & $0.76(0.48$ to 1.21$)$ \\
\hline${ }^{\star}$ p < 0.05; ${ }^{\star \star}$ p $<0.01 ; \star \star \star \mathrm{p}<0.001$.
\end{tabular}

age was found to be more pronounced. Again, from our follow up dataset it cannot be concluded that minor ECG abnormalities have a significant prognostic value.

\section{Discussion}

The ECG has been widely described in the medical literature as a valid and reproducible diagnostic tool for assessing "silent" heart disease. Regarding the evolution in the use of ECGs in epidemiological research, the introduction of the Minnesota code and classification system ${ }^{2}$ has been the most important step in formalising the comparison of ECG findings within and between studies. Many epidemiological studies have demonstrated the association of ECG findings with subsequent
CHD, CVD, and mortality, but most of these studies dealt only with men. The role and significance of ECG findings in women have rarely been documented. Our observations in the BIRNH study allow us now to hypothesise that the prognostic value of common baseline ECG findings for mortality is not different for women compared to men in a large sample of subjects free from symptomatic CHD.

Our results are not in line, however, with those obtained in the 11.5 years' follow up data from the Chicago Heart Association detection project in industry. ${ }^{14}{ }^{18}$ The adjusted RRs for CVD and CHD mortality associated with major and minor ECG abnormalities were found to be higher for men than for women. In their multivariate analysis of the association between ST-T abnormalities and CHD death, the sex difference in RRs was of borderline significance $(p=0.09)$. The authors speculated that the sex difference could possibly be explained by the fact that a higher proportion of ECG changes would reflect underlying severe atherosclerosis in men. ${ }^{14}$ In contrast to these findings, other papers dealing with ECGs in men and women found that changes in the initial ECG had the same prognostic value for CVD or CHD in both sexes. In the 30 year follow up analysis of the Framingham data, Kannel et al reported that non-specific ECG abnormalities of the ST-T type were associated with a twofold increased risk for coronary morbidity and mortality in both men and women. ${ }^{13}$ Similar results were obtained in the Busselton study ${ }^{8}$ where the strength of the effect of separate ECG codes in relation to cardiovascular death in women was comparable to, if not more pronounced than, that in men after 13 years of follow up. Finally, our hypothesis is supported by the recently published results of the Renfrew and Paisley survey ${ }^{24}$ in which, after 15 years of follow up, middle aged men and women with signs of myocardial ischaemia at ECG had a comparable risk for ischaemic heart disease mortality (RR 2.46 for men and 2.26 for women).

Several longitudinal studies have concentrated on the predictive value of baseline ECG findings and subsequent CVD mortality in men. In one of the earliest reports, Rose et al reported significantly increased age adjusted rates for CHD death according to individual Minnesota code items in a large sample of middle aged British male civil servants. ${ }^{4}$ Macfarlane et al found a significant association between possible or definite ECG ischaemia and ischaemic heart disease events in a large sample of men taking part in the British regional heart study. ${ }^{15}$ In the Social Insurance Institution's coronary heart disease study, Reunanen et al found a fivefold increase in CHD mortality for subjects with Minnesota code IV or V abnormalities, ${ }^{5}$ a risk comparable to that observed by Higgins et al in the Framingham study. ${ }^{1}$ These earlier reports, however, are all based on a rather limited follow up period (about five years) and the possible confounding effect of established cardiovascular risk factors was not accounted for. 
In one of the first papers that attempted to deal with ECG findings in a multivariate context, Blackburn et al reported highly significantly increased risks for CHD morbidity and mortality associated with large $\mathrm{Q}$ waves, negative $\mathrm{T}$ waves, atrial fibrillation, premature beats, first degree AV blocks, and minor T waves in 12770 middle aged working men of the Seven Countries study. ${ }^{3}$ In the epidemiological literature, multivariately adjusted effect measures of the association between findings in the baseline ECG and later cardiovascular events became widely available during the last two decades with the development of more complex statistical modelling techniques, such as the proportional hazards model by $\mathrm{Cox},{ }^{31}$ and the availability of faster and more powerful computing systems. In this article we compare our results from men with those obtained from studies that also dealt with comparable ECG classifications and end points in large samples of subjects free from symptomatic CHD.

\section{MAJOR AND MINOR ECG ABNORMALITIES}

As a first step we classified the ECG findings into major and minor abnormalities according to the definition of the pooling project. ${ }^{29}$ Major ECG findings were defined as severe or moderate ST depression (Minnesota code $\mathrm{IV}_{1-2}$ ), deep or moderate $\mathrm{T}$ wave inversion (codes $\mathrm{V}_{1-2}$ ), complete or second degree AV block (codes $\mathrm{VI}_{1-2}$ ), complete left or right bundle branch block (codes $\mathrm{VII}_{1-2,4}$ ), and frequent premature beats, atrial fibrillation or flutter (codes VIII $_{1,3}$ ). In our study, major ECG abnormalities were found to be highly predictive for all cause mortality (multivariately adjusted RR 1.78), CVD (RR 3.07), and CHD death (RR 2.11). Minor ECG findings, including borderline $\mathrm{Q}$ wave (code $\mathrm{I}_{3}$ ), left or right axis deviation (codes $\mathrm{II}_{1-2}$ ), QRS high voltage (codes III $_{1-2}$ ), borderline ST segment depression (code $\mathrm{IV}_{3}$ ), $\mathrm{T}$ wave flattening (code $\mathrm{V}_{3}$ ), and QRS low voltage (code $\mathrm{IX}_{1}$ ) were not associated with any of the end points. These results are very similar to those obtained in the subcohort of white men in the Evans County heart study. ${ }^{16}$ After a 20 year follow up of middle aged men free from CHD, using the same exclusion criteria as we did, multivariately adjusted RRs for major ECG changes were 2.2, 2.2, and 1.8 for all cause, CVD, and CHD mortality, respectively. Moreover, minor abnormalities were also not associated with any of the three end points.

The same conclusion was reached by Sutherland et al after the 30 year follow up of the Charleston heart study cohort of 35 to 74 year old white men. ${ }^{21}$ They reported adjusted RRs for major ECG findings of 2.07 and 2.72 for all cause and CHD death, respectively, while minor ECG findings were not significantly predictive. Also in the Chicago Peoples Gas Company study, ${ }^{9}$ major ECG findings were significantly related to all cause (RR 1.4), CVD (RR 1.6), and CHD (RR 1.5) mortality, in contrast with minor ECG findings which were not significantly related to any of these after 20 years. These results were confirmed in the Chicago Western Electric Company study, ${ }^{9}$ with adjusted RRs for major abnormalities of $1.4,1.7$, and 1.9 for the three respective end points. In this study, however, minor abnormalities were also significantly associated with all three outcomes. The latter results were also obtained in the third Chicago study, the Chicago Heart Association detection project in industry, ${ }^{918}$ in which major (respective RRs 3.3, 5.5, and 6.0) as well as minor ECG abnormalities (RRs 1.9, 2.7, and 2.7) were highly significantly associated with all cause, CVD, and CHD mortality. Finally, a similar conclusion was reached in the Honolulu heart program ${ }^{17}$ where, in about 8000 middle aged men of Japanese ancestry, the risk for fatal CHD after 12 years of follow up in the group with major ECG findings was found to be significantly raised (odds ratio 2.1), while minor ECG findings were of even higher prognostic value (odds ratio 2.4). Although the risks associated with major ECG findings were comparable between all these studies, the heterogeneity of results in subjects with minor ECG findings on the baseline ECG makes prognosis rather unclear.

ISCHAEMIC-LIKE ECG ABNORMALITIES AND ST-T FINDINGS

Many studies dealt with the prognostic value of ST segment changes and $\mathrm{T}$ wave abnormalities for CVD or CHD mortality in men. The results obtained are generally consistent. Most studies reported CVD and CHD death rates associated with these ST-T changes as increased twofold, in accordance with the results published in earlier reports of the Framingham study, ${ }^{13}$ the Busselton study, ${ }^{8}$ and the British regional heart study. ${ }^{15}$ In a more recent publication of data from 9139 men aged 40 to 80 years without CHD at baseline, taking part in the Reykjavik study ${ }^{23}$ and followed up for up to 24 years, a multivariately adjusted RR of 2 was found for CVD death in subjects with "silent ST-T changes" (codes $\mathrm{IV}_{1-4}$ or $\mathrm{V}_{1-3}$ ) on the initial ECG. Schouten et al reported on a Dutch study of 1583 men aged 40 to 65 years in which, after a 15 year follow up, CVD mortality rates were raised by $90 \%$ (RR 1.9) in those with ST segment depression $>0.25 \mathrm{~mm}^{19}$ In the Chicago Heart Association detection project in industry, ${ }^{14}$ the multivariately adjusted RR for CHD mortality associated with ECG abnormalities of the ST-T type (codes $\mathrm{IV}_{1-3}$ or $\mathrm{V}_{1-3}$ ) was found to be 2.6. Finally, according to the 15 year follow up data of the Renfrew and Paisley survey, ${ }^{24}$ the adjusted RR for ischaemic heart disease mortality in men with myocardial ischaemia on their baseline ECG (codes $\mathrm{I}_{1-3}, \mathrm{IV}_{1-4}, \mathrm{~V}_{1-3}$ or VII $_{1}$ ) was 2.46 .

Our findings are in complete agreement with the results from all these studies. In our study, an ischaemia-like ECG (codes $\mathrm{I}_{3}, \mathrm{IV}_{1-3}, \mathrm{~V}_{1-3}$ or $\mathrm{VII}_{1}$ ) was significantly associated with CVD and CHD mortality with adjusted RRs of 2.36 and 1.68, respectively. As for individual ECG codes, ST segment depression (codes $\mathrm{IV}_{1-3}$ ) was, in our study, the most predictive independent ECG finding for all three end points under study. In men, the adjusted RR associated with an ST 
depression, after correction for cardiovascular risk factors and other major ECG abnormalities, were 4.28 and 3.49 for CVD and CHD death, respectively. The independent prognostic value of $\mathrm{T}$ wave changes (codes $\mathrm{V}_{1-3}$ ) turned out to be less pronounced, with adjusted RRs of 2.40 and 2.05. These results are completely in line with the observations made in the Honolulu heart program. ${ }^{17}$ In that study, Knutsen et al report adjusted odds ratios for fatal CHD of 3.7 for major ST depression (codes $\mathrm{IV}_{1-2}$ ) and 3.3 for major $\mathrm{T}$ wave inversion (codes $\mathrm{V}_{1-2}$ ).

\section{ARRHYTHMIAS}

With data from the Framingham Heart study, Bikkina et al found a significant twofold increase in all cause and CHD death in persons with asymptomatic complex or frequent ventricular beats. ${ }^{20}$ In order to obtain sufficient statistical power, we used a much broader definition for arrhythmias by including ventricular and supraventricular tachycardia, atrial fibrillation or flutter, idioventricular and atrioventricular nodal rhythm, and all Minnesota code VI abnormalities (second or third degree AV block and Wolff-Parkinson-White phenomenon). This pooling of codes resulted in significantly raised risks for all three outcomes. Combining data from both sexes, we find multivariate adjusted risks of $1.35,2.15$, and 1.94 , respectively for all cause, CVD, and CHD death.

\section{BUNDLE BRANCH BLOCKS}

In the report by Rose et al on the large database of 18000 civil servants, ventricular conduction defects were found to be associated with a significant twofold to threefold increased risk for CHD mortality. ${ }^{4}$ In the early Seven Countries study report, ${ }^{3}$ however, neither right nor left bundle branch blocks were found to be predictive for CHD death, but this result was based on only two deaths. In the analysis of follow up data from the Chicago Western Electric Company study, Liao et al also found no increased risk of death from CHD and CVD in persons with incomplete right bundle branch block. ${ }^{12}$ In the Reykjavik study ${ }^{22}$ a significantly higher mortality from heart disease was found in men and women with right bundle branch block, but the significance of the association disappeared in the multivariate Cox regression analysis, mainly because of the confounding effect of underlying cardiovascular findings such as hypertension and raised blood glucose concentrations. Right bundle branch block did not increase the risk of fatal CHD in the Honolulu heart program. ${ }^{17}$ The authors even suggested eliminating this ECG finding from the definition of major ECG abnormalities of the pooling project criteria. ${ }^{29}$ In the Framingham study, however, Schneider et al found that newly acquired right bundle branch block did increase CHD incidence rates by a factor of 2.5 to $4 .^{6}$ Our definition of ventricular conduction defects includes right and left bundle branch block. In a separate analysis (results not shown) we studied in detail the prognostic value of right bundle branch block (code $\mathrm{VII}_{2}$ ), which resulted in multivariately adjusted RRs of 2.36 (95\% CI 1.21-4.62) for CVD mortality and
2.89 (1.26-6.60) for CHD mortality. For the analysis of left bundle branch block, comparable results were obtained for CVD mortality while an association with $\mathrm{CHD}$ death was absent. Hence, in our dataset we find evidence that bundle branch blocks, left or right, carry an increased risk for CVD mortality and, to a lesser extent, for CHD mortality.

\section{LEFT AXIS DEVIATION}

In the Honolulu heart program, ${ }^{17}$ a significant twofold increase in fatal CHD rates was observed in men with a left axis deviation (code $\mathrm{II}_{1}$ ) on their initial ECG. A comparable significant risk for CVD death associated with this ECG finding was found in the middle aged men of the Busselton study (RR 1.6). ${ }^{8}$ In the Social Insurance Institution's coronary heart disease study, ${ }^{5}$ however, no increased risk for CHD death related to ECG left axis deviation was found in men without symptoms or signs of CHD at the beginning of the study. This result is in agreement with that reported by Blackburn et al using data from the Seven Countries study in which the incidence of CHD was not significantly raised in the group with left axis deviation on their ECG. ${ }^{3}$ The results from our study suggest a positive association between left axis deviation and CHD, with a $50 \%$ higher death rate in the group having this ECG finding. Owing to lack of statistical power, the observed adjusted RR was not significantly different from 1 .

LEFT VENTRICULAR HYPERTROPHY

LVH has been identified as an independent contributor to risk of sudden cardiac death and may be considered an important predictive factor for lethal arrhythmias. ${ }^{10}{ }^{11} \mathrm{LVH}$ has been found to be a complication of underlying diseases, including hypertensive heart failure with or without atherosclerosis, valvar heart disease, and others. Observations in middle aged men from the Framingham study ${ }^{30}$ and the Honolulu heart program, ${ }^{17}$ support a strong association between the ECG pattern of LVH and subsequent CHD mortality. The definition of LVH in these studies was the same as ours, as it was not only based on the QRS voltage, but included ST segment changes, T wave abnormalities, or both. In our sample of men, LVH was found to be significantly associated with CVD death (RR 3.14); however, the association with fatal CHD did not reach the $5 \%$ significance level (RR 1.84), probably because of lack of power since only two CHD deaths occurred in men with evidence of LVH on their ECG.

CONCLUSIONS

Our BIRNH study is not characterised by a high participation rate and hence findings could be subject to selection bias. However, analysis of a $10 \%$ non-respondent sample revealed no major differences in lifestyle related characteristics between participants and non-participants. ${ }^{26}$ Another argument favouring acceptable external validity for our study can be found in the mortality experience over the 10 years of follow up. The age and sex 
specific total mortality rates for the BIRNH participants were comparable to the estimates from official age and sex specific national mortality statistics in our country. Moreover, the prevalence figures of ECG findings in our sample are comparable to those reported for other studies in Europe, such as the Renfrew and Paisley survey. ${ }^{24}$ Nevertheless, selection bias cannot be discarded from our study and the associations observed may be distorted.

The strength of the association between ECG findings and subsequent CVD and CHD mortality is particularly interesting when comparing their prognostic value with that of established risk factors such as hypertension, diabetes, smoking, hyperlipidaemia, obesity, and sex. Our observations suggest that major changes on the baseline ECG are of greatest importance for later CVD and CHD mortality, with an independent predictive value which is only exceeded by the effect of age. To our knowledge this is the only report showing this high relative importance of ECG findings compared to classic cardiovascular risk factors.

In conclusion, the results from our study indicate that in subjects clinically free from CHD, findings on the baseline ECG are strongly related to a higher risk for all cause, CVD, and CHD mortality, independent of established risk factors. The predictive value of the ECG findings in our study was found to be the same for both sexes. Hence, from our observations, we conclude that the clinical judgment of findings on the resting ECG should not be different for men and women.

1 Higgins IT, Kannel WB, Dawber TR. The electrocardiogram in epidemiological studies: reproducibility, validity and international comparison. $\mathrm{Br} \quad \mathrm{f} \mathrm{Prev}$ Soc $\mathrm{Med}$ 1965;19:53-68

2 Blackburn H, Keys A, Simonson E, et al. The electrocardiogram in population studies. A classification system Circulation 1960;21:1160-75.

3 Blackburn H, Taylor HL, Keys A. The electrocardiogram in prediction of five-year coronary heart disease incidence among men aged 40 through 59. Circulation 1970 42(suppl): 154-61

4 Rose GA, Baxter PJ, Reid DD, et al. Prevalence and prognosis of electrocardiographic findings in middle-aged men. $B$ Heart f 1978;40:636-43.

5 Reunanen A, Pyörälä K, Punsar S, et al. Predictive value of ECG findings with respect to coronary heart disease mortality. Adv Cardiol 1978;21:310-2.

6 Schneider JF, Thomas HE, Kreger BE, et al. Newly acquired right bundle branch block: the Framingham study. Ann Intern Med 1980;92:37-44.

7 Barret PA, Peter CT, Swan HJ, et al. The frequency and prognostic significance of electrocardiographic abnormalities in clinically normal subjects. Prog Cardiovasc Dis 1981 23:299-319.

8 Cullen K, Stenhouse NS, Wearne KL, et al. Electrocardiograms and 13-year cardiovascular mortality in the Busselton study. Br Heart $\mathcal{f}$ 1982;47:209-12.

9 Cedres BL, Liu K, Stamler J, et al. Independent contribution of electrocardiographic abnormalities to risk of death from coronary heart disease, cardiovascular diseases and all causes. Findings of three Chicago epidemiologic studies. Circulation 1982;65:146-53.
10 Anderson KP. Hypertension and sudden cardiac death. NZ Med F 1982;95:33-4

11 Messerli PH, Ventura HO, Elizardi DJ. Hypertension and sudden death: increased ventricular ectopic activity in left ventricular hypertrophy. Am f Med 1984;77:18-22.

12 Liao YL, Emidy LA, Dyer A, et al. Characteristics and prognosis of incomplete right bundle branch block: an epidemiologic study. 7 Am Coll Cardiol 1986;7:492-9.

13 Kannel WB, Anderson K, McGee DL, et al. Nonspecific electrocardiographic abnormality as a predictor of coronary heart disease: the Framingham heart study. Am Heart $\mathcal{F}$ 1987;113:370-6.

14 Liao Y, Liu K, Dyer A, et al. Sex differential in the relationship of electrocardiographic ST-T abnormalities to risk of coronary death: 11.5 year follow-up findings of the Chicago Heart Association detection project in industry. Circulation 1987;75:347-52.

15 Macfarlane PW. British regional heart study: The electrocardiogram and risk of myocardial infarction on follow-up. 7 Electrocardiol 1987;20 (suppl):53-6.

16 Strogatz DS, Tyroler HA, Watkins LO, et al. Electrocardiographic abnormalities and mortality among middle-aged black and white men of Evans county, Georgia. 7 Chron Dis 1987;40:149-55.

17 Knutsen R, Knutsen SF, Curb D, et al. The predictive value of resting electrocardiograms for 12-year incidence of coronary heart disease in the Honolulu heart program. $7 \mathrm{Clin}$ Epidemiol 1988;41:293-302.

18 Liao Y, Liu K, Dyer A, et al. Major and minor electrocardiographic abnormalities and risk of death from coronary heart disease, cardiovascular diseases and all causes in men and women. 7 Am Coll Cardiol 1988;12:1494-500.

19 Schouten EG, Dekker JM, Pool J, et al. Well shaped ST segment and risk of cardiovascular mortality. BMF 1992;304: 356-9.

20 Bikkina M, Larson MG, Levy D. Prognostic implications of asymptomatic ventricular arrhythmias: the Framingham heart study. Ann Intern Med 1992;117:990-6.

21 Sutherland SE, Gazes PC, Keil JE, et al. Electrocardiographic abnormalities and 30-year mortality among white and black men of the Charleston heart study. Circulation 1993;88:2685-92.

22 Thrainsdottir IS, Hardarson T, Thorgeirsson G, et al. The epidemiology of right bundle branch block and its association with cardiovascular morbidity. The Reykjavik study. Eur Heart f 1993;14:1590-6.

23 Sigurdsson E, Sigfusson N, Sigvaldason H, et al. Silent ST-T changes in an epidemiologic cohort study-a marker of hypertension or coronary heart disease, or both: the Reykjavik study. F Am Coll Cardiol 1996;27:1140-7.

24 Hart CL, Watt GCM, Davey Smith G, et al. Pre-existing ischaemic heart disease and ischaemic heart disease mortality in women compared with men. Int $\mathcal{F}$ Epidemiol 1997;26:508-15.

25 De Backer G. Nutrition and health: an interuniversity study. Regional differences in dietary habits, coronary risk factors and mortality rates in Belgium. I. Design and methodology. Acta Cardiol 1984;39:285-92.

26 Kornitzer M, Dramaix M. The Belgian inter-university research on Nutrition and Health (BIRNH) study. Acta Cardiol 1989;94:89-99.

27 Rose GA, Blackburn H, Gillum RF, et al. Cardiovascular survey methods. World Health Organization Geneva Monograph Series 56, 2nd edn, 1982.

28 World Health Organization. Manual of the International Classification of Diseases, $9^{\text {th }}$ revision. Geneva: WHO, 1977.

29 The Pooling Project Research Group. Relationship of blood pressure, serum cholesterol, smoking habits, relative weight and ECG abnormalities to incidence of major coronary events: final report of the pooling project. $f$ Chron Dis 1978;31:201-306.

30 Shurtleff D. Some characteristics related to the incidence of cardiovascular disease death: Framingham study, 18 year follow up. In: Kannel WB, Gordon T, eds. The Framingham study-an epidemiological investigation of cardiovascular disease. Washington, DC. US DHEW USPHS, NIH, DHEW publ. (NIH) 74-599. 1994

31 Cox DR, Oakes D. Analysis of survival data. Monographs on Statistics and Applied Probability. Cambridge: Chapman and Hall, 1984.

32 The SAS system for Windows, Release 6.11.SAS Institute Inc, Cary, North Carolina, USA. 